\title{
HEART
}

\section{Gender differences in the implementation of cardiovascular prevention measures after an acute coronary event}

Jean Dallongevillle, Dirk De Bacquer, Jan Heidrich, et al.

Heart 2010 96: 1744-1749

doi: $10.1136 /$ hrt.2010.196170

Updated information and services can be found at:

http://heart.bmj.com/content/96/21/1744.full.html

These include:

References This article cites 27 articles, 15 of which can be accessed free at: http://heart.bmj.com/content/96/21/1744.full.html\#ref-list-1

Email alerting Receive free email alerts when new articles cite this article. Sign up in the service box at the top right corner of the online article.

\section{Notes}

To request permissions go to:

http://group.bmj.com/group/rights-licensing/permissions

To order reprints go to:

http://journals.bmj.com/cgi/reprintform

To subscribe to BMJ go to:

http://journals.bmj.com/cgi/ep 


\title{
Gender differences in the implementation of cardiovascular prevention measures after an acute coronary event
}

\author{
Jean Dallongevillle, ${ }^{1}$ Dirk De Bacquer, ${ }^{2}$ Jan Heidrich, ${ }^{3}$ Guy De Backer, ${ }^{2}$ \\ Christoph Prugger, ${ }^{3}$ Kornelia Kotseva, ${ }^{4}$ Michèle Montaye, ${ }^{1}$ Philippe Amouyel, ${ }^{1}$ \\ on behalf of the EUROASPIRE Study Group
}

\begin{abstract}
- An additional table is published online only. To view this file please visit the journal online (http://heart.bmj.com).

${ }^{1}$ MONICA Lille project, Institut Pasteur de Lille, INSERM U744, Lille, France

${ }^{2}$ Department of Public Health, Ghent University, Ghent, Belgium

${ }^{3}$ Institute of Epidemiology and Social Medicine, University of Münster, Münster, Germany ${ }^{4}$ Cardiovascular Medicine, National Heart and Lung Institute, Imperial College London, UK
\end{abstract}

\section{Correspondence to}

Dr Jean Dallongeville, Department of Epidemiology and Public Health, INSERM U744, Institut Pasteur de Lille, 1 rue du Pr Calmette, 59019 Lille, France; jean.dallongeville@ pasteur-lille.fr

Accepted 27 July 2010

\section{ABSTRACT}

Objective To compare gender-related lifestyle changes and risk factor management after hospitalisation for a coronary event or revascularisation intervention in Europe.

Method The EUROASPIRE III survey was carried out in 22 European countries in 2006-2007. Consecutive patients having had a coronary event or revascularisation before the age of 80 were identified. A total of 8966 patients (25.3\% women) were interviewed and underwent clinical and biochemical tests at least 6 months after hospital admission. Trends in cardiovascular risk management were assessed on the basis of the 1994-1995, 1999-2000 and 2006-2007 EUROASPIRE surveys.

Results Female survey participants were generally older and had a lower educational level than male participants $(p<0.0001)$. The prevalences of obesity $(p<0.0001)$, high blood pressure (BP) $(p=0.001)$, elevated lowdensity lipoprotein (LDL)-cholesterol $(p<0.0001)$ and diabetes $(p<0.0001)$ were significantly higher in women than in men, whereas current smoking $(p<0.0001)$ was significantly more common in men. The use of antihypertensive and antidiabetic drugs (but not that of other drugs) was more common in women than in men. However, BP $(p<0.0001)$, LDL-cholesterol $(p<0.0001)$ and $\mathrm{HbA1c}(p<0.0001)$ targets were less often achieved in women than in men. Between 1994 and 2007, cholesterol control improved less in women than in men (interaction: $p=0.009$ ), whereas trends in BP control $(p=0.32)$ and glycaemia $(p=0.36)$ were similar for both genders

Conclusion The EUROASPIRE III results show that despite similarities in medication exposure, women are less likely than men to achieve BP, LDL-cholesterol and $\mathrm{HbA} 1 \mathrm{c}$ targets after a coronary event. This gap did not appear to narrow between 1994 and 2007.

\section{INTRODUCTION}

Coronary heart disease mortality rates are lower in women than in men. They start to increase at the age of 40 years in men and approximately 10 years later in women. ${ }^{1}{ }^{2}$ In contrast, during and immediately after a coronary event or a percutaneous transluminal coronary angioplasty (PTCA), mortality is higher in women than in men. ${ }^{3-8}$ This difference is especially marked in younger patients and tends to narrow with age. However, the longterm outcome after a myocardial infarction (MI) is still worse in elderly women than men and narrows women's survival advantage over men. ${ }^{6}$

Several hypotheses may explain the excess mortality in women after an acute MI (see Shae et al ${ }^{9}$ for review). First, from an anatomical point of view, the female vascular bed is smaller and less compliant, which increases the risk of complications. ${ }^{10}$ Second, the symptomatology of cardiac ischaemia is more often ambiguous and may lead to a delay in receiving appropriate care. ${ }^{11} 12$ Third, comorbidities are more common in women than in men presenting with a first $\mathrm{MI}$ and thus result in worse functional status. ${ }^{8} 13-15$ Lastly, less intense management in women during the immediate postMI phase has been reported ${ }^{16}$ but has not been confirmed in the most recent studies. ${ }^{17-19}$

There is now ample evidence from observational epidemiological surveys and randomised controlled trials that appropriate lifestyles and pharmacological treatment can prevent recurrent events and improve survival in patients with established coronary heart disease (CHD). ${ }^{20} 21$ The EUROASPIRE programme is a multicentre European survey which aims at assessing how the clinical guidelines on cardiovascular disease prevention are implemented in daily practice in European countries. Data of interest were collected directly in patient interviews and clinical examination by trained staff according to standardised procedures. The results of the EUROASPIRE programme have revealed adverse lifestyle trends in patients with $\mathrm{CHD}$ and a failure to achieve recommended therapeutic targets. ${ }^{22-26}$

In order to better understand the gender differences in mortality that may occur after a coronary event, we hypothesised that CHD management might differ in women and men after hospitalisation for a coronary event or revascularisation intervention. The extent to which therapeutic targets are met in each gender has not been clearly established. Therefore, the goal of this study was to compare cardiovascular disease management in men and women at least 6 months after hospitalisation for a coronary event or a revascularisation intervention. One of the advantages of this strategy is that all patients went through the cardiology wards and should receive similar high-standard management of their disease, no matter what their gender or age. Based on the results of EUROASPIRE I, II and III, we also looked at whether patient management and achievement of therapeutic targets has changed over 
time (between 1994 and 2007) in the same way in men and women in the eight countries which have participated in the three surveys.

\section{METHODS}

The details of the study protocol are reported elsewhere. ${ }^{25}$ Briefly, EUROASPIRE III was performed in 2006-7 in 22 European countries. Within each country, one or more geographical areas with a defined population were selected and all hospitals serving this population were identified. A sample of one or more hospitals, or all hospitals, was taken so that any patient presenting within the area with acute symptoms of coronary disease, or requiring revascularisation had an approximately equal chance of being included. Patients admitted to a hospital outside this geographical area were not included in the sample.

Within each hospital, consecutive patients (men and women $\geq 18$ years and $<80$ years of age at the time of identification, with first or recurrent diagnosis or treatments for $\mathrm{CHD}$ - see below) were identified retrospectively from diagnostic registers, hospital discharge lists or other sources. Patients had to fulfil one or more of the following diagnostic criteria: (i) coronary artery bypass graft; (ii) PTCA; (iii) MI; (iv) acute myocardial ischaemia but no evidence of MI (unstable angina) at least 6 months and not more than 3 years before the expected interview date.

Data were collected by trained research staff who interviewed and examined the patients at hospital or at home using standardised procedures and instruments. The following information was obtained in the interview: personal and demographic details; personal cardiovascular history (including stroke, transient ischaemic attacks and peripheral artery disease); other aspects of the personal medical history, including hypertension, hyperlipidaemia and diabetes; a family history of CHD for patients with premature disease (men under 55 and women under 65); stated lifestyle and other risk factors in relation to smoking; diet (including weight reduction); exercise; blood pressure (BP); lipids and glucose; medication (generic names and the total daily dose); educational level; school attendance and employment status.

The following measurements were performed: height and weight in light indoor clothes without shoes (SECA 701 scales and measuring stick model 220); waist circumference; sitting BP (measured twice on the right upper arm using an Omron M5-I automatic digital sphygmomanometer (Omron Healthcare, Kyoto, Japan)); heart rate and breath carbon monoxide (Micro 4 Smokerlyser, Bedfont Scientific, Rochester, UK). Venous blood was tested for serum total cholesterol, high-density lipoprotein (HDL)-cholesterol, triglycerides, calculated LDL-cholesterol, plasma glucose and (in patients with diabetes) HbA1c. Obesity was defined as a body mass index (BMI) $\geq 30 \mathrm{~kg} / \mathrm{m}^{2}$ and central obesity was defined as waist girth $\geq 102 \mathrm{~cm}$ for men and $\geq 88 \mathrm{~cm}$ for women. Hypertension was defined as $B P \geq 140 / 90 \mathrm{~mm} \mathrm{Hg}$ (or, in diabetic patients, $\geq 130 / 80 \mathrm{~mm} \mathrm{Hg}$ ). Dyslipidaemia was defined as LDL-cholesterol $\geq 2.5 \mathrm{mmol} / \mathrm{l}$ or cholesterol $\geq 5 \mathrm{mmol} / \mathrm{l}$. Diabetes was considered to be fasting glycaemia $\geq 7 \mathrm{mmol} / \mathrm{l}$ and/or administration of antidiabetic agents.

In order to standardise the measurements taken, all equipment was calibrated and serviced according to the manufacturer's recommendations. Venous blood samples were handled and stored according to guidelines prepared by the central Laboratory of Analytical Biochemistry at the Finnish National Public Health Institute (Helsinki, Finland). All national coordinators and the main research staff responsible for teaching the local data collectors were trained at the Coordinating Center at the Department of Cardiovascular Medicine, National Heart and Lung Institute, Imperial College London (London, UK). Although other laboratories were used In EUROASPIRE I and II, comparisons were made to ensure that the three datasets and procedures were comparable.

Data management was undertaken at the European Society of Cardiology Euro Heart Survey Department, European Heart House (Nice, France). All data were collected electronically using a unique country, centre and participant identification number. The data were submitted via internet to the data management centre, where checks for completeness, internal consistency and accuracy were run. For most variables data are missing for $<1 \%$ (see online supplementary table), except blood values due to logistic reasons and non-fasting; 33\% of $\mathrm{HbA} 1 \mathrm{c}$ results were missing. No attempt was made to correct for missing data. The proportion of missing values did not different between men and women and hence will not affect our main conclusions. All data were stored according to the provisions of the national data protection regulations.

National coordinators were responsible for obtaining approval from the appropriate local review boards. Written, informed consent was obtained from each participant by the investigator by means of a signed declaration. The research assistants signed the survey's case report form to confirm that informed consent had been obtained and then stored the original, signed declaration of consent in the corresponding patient file.

\section{Trend analysis}

For trend analysis, the same geographical areas and hospitals were used in the countries (the Czech Republic, Finland, France, Germany, Hungary, Italy, the Netherlands and Slovenia) that participated in EUROASPIRE I (1994-1995), II (1999-2000) and III (2006-2007) surveys. ${ }^{25} 26$ Spain participated in all three surveys but the investigating centres changed from one survey to another and so the country was excluded from trend analysis. Consecutive patients of either gender were identified as having undergone revascularisation (coronary artery bypass graft and PTCA) or having been admitted to hospital with acute MI or myocardial ischaemia (without enzyme elevation) and were reexamined at least 6 months later. Since the age at inclusion was $\leq 70$ years in the first two surveys, our analyses were restricted to this age class. The overall participation rate was $77.2 \%$ in EUROASPIRE I, $76.5 \%$ in EUROASPIRE II and $68.4 \%$ in EUROASPIRE III.

The methods used to ensure comparability of the three surveys have been specified elsewhere. ${ }^{25}$ Briefly, a similar type of scale was used for each survey and the scales were calibrated at the start of the surveys. Similar, automatic digital sphygmomanometers were used: the Takeda UA 731 (Takeda Medical, Tokyo, Japan) in EUROASPIRE I, the Omron 711 in EUROASPIRE II and Omron M5-I in EUROASPIRE III. The sphygmomanometers' performance levels were compared and a correction factor was applied as required. Venous blood was drawn for measurement of the cholesterol concentration in plasma (EUROASPIRE I) or serum (EUROASPIRE II and III). A variety of analysers were used for cholesterol assessment and the performance levels were compared. As a result, the individual cholesterol concentrations from EUROASPIRE I were corrected by a factor of 1.13 for comparative purposes. Plasma glucose concentrations were measured by a variety of methods in each survey but these were not standardised for comparison. In EUROASPIRE I, the plasma glucose concentration was measured with the hexokinase method on a Technicon Axon Chemistry Analyser (Miles, Tarrytown, New York, USA). In 
EUROASPIRE II, the plasma glucose concentration was measured from lithium heparin samples using a hexokinasebased assay running on a Bayer Axon analyser (Bayer, Leverkusen, Germany). The coefficient of variation was $2.8 \%$. In EUROASPIRE III, plasma glucose was measured in fluoridecitrate samples with a hexokinase-based assay on a clinical chemistry analyser (Architect c8000, Abbott Laboratories, Abbott Park, Illinois, USA). The coefficient of variation was $1.7 \%$.

\section{Statistical analyses}

Descriptive statistics were used to estimate the prevalence and distribution of risk factors and drug use by gender. Risk factor prevalences for men and women were compared in mixed effects logistic regression analyses that took account of patient clustering within centres (modelled as a random effect). Age at interview was modelled as an additional covariate. Gender differences according to age were evaluated by including an age ( $<60$ years vs $\geq 60$ years) by gender interaction term in the model. The statistical significance threshold was set to $p=0.05$. All statistical analyses were performed with SAS software (version 9.1, SAS Institute, Cary, North Carolina, USA) in the Department of Public Health, Ghent University (Ghent, Belgium).

\section{RESULTS}

\section{Characteristics of the survey population}

A total of 2268 women (25.3\%) and 6698 men (74.7\%) were interviewed (table 1). Overall, the women were older and had a lower educational level than the men and were more likely to have had acute ischemia as an inclusion criterion. In contrast, current smoking was more common in men. BMI, obesity, abdominal obesity, high BP, elevated LDL-cholesterol, HDLcholesterol, self-reported diabetes, HbA1c levels and elevated $\mathrm{HbA1c}$ in diabetic subjects were higher in women than in men independently of age. These associations did not differ when comparing younger and older patients (ie, statistically significant gender-by-age interactions). In contrast, total diabetes was more common in women than in men in the under-60s but not in older patients (interaction $\mathrm{p}=0.009$ ).

\section{Medical treatment at interview}

The average rate of participation in cardiac rehabilitation programmes and prescription of antithrombotic drugs and ACE inhibitors were lower in women than in men (table 2). In contrast, there were no gender differences in statins and $\beta$-blockers prescription rates. Prescription of other drugsnamely, angiotensin II receptor blockers, calcium antagonists, nitrates, diuretics, insulin and oral antidiabetic agents, was more common in women than in men. These results were homogeneous in young and old patients ( $p>0.1$ for all gender-by-age interaction).

\section{Medical management and achievement of therapeutic targets}

Advice for smoking cessation after the acute event and persistence of smoking among former smokers was equally distributed between men and women (table 3). In obese patients, women preferred dietary recommendations and men preferred physical exercise for body weight control. The use of antihypertensive drugs and antidiabetic agents was more prevalent in women than in men, as were high BP and high HbA1c levels in treated patients. Lastly, prescription of hypolipidaemic drugs was similar in men and women but LDL-cholesterol levels were more
Table 1 Patient's characteristics and cardiovascular risk factors at interview: EUROASPIRE III

\begin{tabular}{|c|c|c|c|}
\hline & Men & Women & p Value $\dagger$ \\
\hline$N(\%)$ & $6698(74.7)$ & $2268(25.3)$ & \\
\hline Age at interview, mean (SD) & $62.2(9.6)$ & $65.8(9.0)$ & $<0.0001$ \\
\hline Index event & & & $<0.0001$ \\
\hline CABG (\%) & 20.4 & 17.2 & \\
\hline PTCA (\%) & 43.5 & 35.4 & \\
\hline AMI (\%) & 19.1 & 20.6 & \\
\hline Ischaemia (\%) & 17.0 & 26.8 & \\
\hline Education level & & & $<0.0001$ \\
\hline Years of school (median) & 12.0 & 11.0 & \\
\hline Primary & 22.5 & 33.5 & \\
\hline Secondary & 39.6 & 37.0 & \\
\hline Intermediate & 17.6 & 17.8 & \\
\hline Higher & 20.2 & 11.8 & \\
\hline Current smokers $(\%)$ & 19.3 & 11.0 & $<0.0001$ \\
\hline BMI $\left(\mathrm{kg} / \mathrm{m}^{2}\right)$, mean (SD) & $28.6(4.2)$ & $29.8(5.2)$ & $<0.0001$ \\
\hline Obesity $\left(\mathrm{BMI} \geq 30 \mathrm{~kg} / \mathrm{m}^{2}\right)(\%)$ & 32.1 & 44.7 & $<0.0001$ \\
\hline Waist $(\mathrm{cm})$, mean (SD) & $100.8(11.7)$ & $95.8(13.6)$ & $<0.0001$ \\
\hline $\begin{array}{l}\text { Central obesity (waist } \geq 102 / 88 \mathrm{~cm} \text { in } \\
\text { men/women (\%) }\end{array}$ & 45.6 & 73.5 & $<0.0001$ \\
\hline $\mathrm{SBP}(\mathrm{mm} \mathrm{Hg})$, mean (SD) & $139.5(20.2)$ & $142.5(22.2)$ & 0.0001 \\
\hline $\mathrm{DBP}(\mathrm{mm} \mathrm{Hg})$, mean $(\mathrm{SD})$ & $82.7(11.7)$ & $82.9(12.0)$ & 0.02 \\
\hline Pulse pressure $(\mathrm{mm} \mathrm{Hg})$, mean (SD) & $56.8(14.7)$ & $59.6(16.8)$ & 0.001 \\
\hline Raised $B P(B P \geq 140 / 90 \mathrm{~mm} \mathrm{Hg})(\%)$ & 49.0 & 54.5 & 0.001 \\
\hline Raised blood pressure $(\%)^{*}$ & 80.3 & 87.9 & $<0.0001$ \\
\hline LDL-cholesterol (mmol/) & $2.7(0.9)$ & $3.0(1.1)$ & $<0.0001$ \\
\hline Raised LDL ( $\geq 2.5 \mathrm{mmol} / \mathrm{l})(\%)$ & 52.4 & 61.1 & $<0.0001$ \\
\hline HDL-cholesterol (mmol/l), mean (SD) & $1.1(0.3)$ & $1.3(0.3)$ & $<0.0001$ \\
\hline $\begin{array}{l}\text { Fasting triglycerides }(\mathrm{mmol} / \mathrm{l}) \text {, mean } \\
\text { (range) }\end{array}$ & $1.4(1.0-2.0)$ & $1.4(1.0-1.9)$ & 0.44 \\
\hline Glycaemia (mmol/l), mean (SD) & $7.0(2.1)$ & $7.21(2.7)$ & 0.02 \\
\hline Self reported diabetes $(\%)$ & 22.6 & 30.4 & $<0.0001$ \\
\hline Glycaemia $\geq 7 \mathrm{mmol} / \mathrm{l})(\%)$ & 28.2 & 29.7 & 0.55 \\
\hline Total diabetes (\%) & 33.6 & 38.4 & $0.009 \ddagger$ \\
\hline $\begin{array}{l}\text { HbA1c in diabetic subjects (\%), mean } \\
\text { (SD) }\end{array}$ & $7.1(1.4)$ & $7.6(1.7)$ & $<0.0001$ \\
\hline $\mathrm{HbA} 1 \mathrm{c} \geq 6.5 \%$ in diabetic subjects $(\%)$ & 61.4 & 74.1 & $<0.0001$ \\
\hline $\mathrm{HbA} 1 \mathrm{c} \geq 7 \%$ in diabetic subjects (\%) & 46.1 & 60.1 & $<0.0001$ \\
\hline
\end{tabular}

Total diabetes: known and/or raised glycaemia.

$\mathrm{HbA1C}$ was measured in patients with known diabetes only.

${ }^{*} \mathrm{BP} \geq 140 / 90$ or $\mathrm{BP} \geq 130 / 80 \mathrm{~mm} \mathrm{Hg}$ for diabetic patients or treatment for known HTA †Significance between sexes adjusted for age and centre.

$\neq$ Significance of the gender-by-age interaction adjusted for centre.

AMI, acute myocardial infarction, BMI, body mass index; BP, blood pressure; CABG, coronary artery bypass grafting; DBP, diastolic blood pressure; LDL, low-density lipoprotein; PTCA, percutaneous transluminal coronary angioplasty; SBP, systolic blood pressure.

often above target in treated women than in treated men. These results were homogeneous in young and old patients $(p>0.1$ for all gender-by-age interactions).

\section{Trends in risk factors, their management and achievement of therapeutic targets}

Between 1994 and 2007, the prevalence of active smokers $(p=0.64)$ and high BP $(p=0.79)$ remained stable, whereas that of obesity $(p<0.0006)$ and diabetes $(p=0.004)$ rose (figure 1$)$. These trends were similar for both genders $(p>0.1$ for all gender-bysurvey interactions). In contrast, raised cholesterol decreased between 1994 and 2007-an improvement that was less pronounced in women than in men (interaction: $p<0.0001$ ). Further, interaction testing demonstrated that for both genders, the trends in the prevalence of smoking (age-by-survey interaction: $p=0.34$ and $p=0.80$ in men and women, respectively), obesity ( $p=0.46, p=0.47)$, high BP $(p=0.76, p=0.52)$, diabetes 
Table 2 Medical treatment after index event at interview: EUROASPIRE III

\begin{tabular}{lrcc}
\hline & Men & Women & p Value* \\
\hline Secondary prevention treatment & & & \\
$\quad$ Aspirin or antiplatelets & 91.2 & 88.3 & 0.03 \\
$\beta$ Blockers & 79.4 & 80.8 & 0.51 \\
Statins & 78.9 & 75.7 & 0.39 \\
ACE & 60.2 & 59.2 & 0.01 \\
Angiotensin II receptor antagonist & 10.9 & 15.3 & $<0.0001$ \\
Cardiovascular risk factor treatment & & & \\
Anticoagulants & 5.7 & 5.4 & 0.07 \\
Calcium antagonists & 22.3 & 30.7 & $<0.0001$ \\
Nitrates & 26.0 & 34.5 & $<0.0001$ \\
Diuretics & 26.4 & 41.3 & $<0.0001$ \\
Insulin & 5.5 & 8.8 & $<0.0001$ \\
Oral antidiabetic agent & 13.6 & 17.0 & 0.0003 \\
\hline
\end{tabular}

Results are shown as percentages.

${ }^{*}$ Significance between sexes adjusted for age and centre.

$(p=0.58, p=0.17)$ and raised cholesterol $(p=0.07, p=0.18)$ did not differ significantly when comparing younger patients ( $<60$ years) and older patients $(\geq 60$ years).

The prescription of all prophylactic drugs rose between 1994 and 2007 (table 4). This change was similar in men and women for all drugs except antiplatelet agents, the use of which increased more quickly in women than in men (interaction: $p=0.003$ ). Finally, we also looked at whether BP, cholesterol and glycaemia targets were reached in patients being treated for these risk factors. Between 1994 and 2007, the extent of BP control remained stable and that of glycaemia deteriorated.

Table 3 Medical management after index event at interview: EUROASPIRE III

\begin{tabular}{|c|c|c|c|}
\hline & Men & Women & p Value * \\
\hline Cardiac rehabilitation attendance $\dagger$ & 34.9 & 31.0 & 0.002 \\
\hline \multicolumn{4}{|l|}{ Advice given to current smokers } \\
\hline Verbal & 91.3 & 87.7 & 0.10 \\
\hline Written & 34.3 & 36.7 & 0.83 \\
\hline Clinic & 14.1 & 15.4 & 0.67 \\
\hline Smoking among former smokers & 51.9 & 51.9 & 0.91 \\
\hline \multicolumn{4}{|l|}{ Action taken to control excess body weight } \\
\hline Following dietary advice & 50.3 & 55.1 & 0.04 \\
\hline Regular physical activity & 40.3 & 33.8 & 0.01 \\
\hline Weight reduction drugs & 1.8 & 2.3 & 0.31 \\
\hline None & 39.2 & 39.5 & 0.59 \\
\hline \multicolumn{4}{|l|}{ Hypertension } \\
\hline Use of antihypertensive drugs & 66.8 & 80.1 & $<0.0001$ \\
\hline $\begin{array}{l}\text { Raised blood pressure } \neq \text { in treated } \\
\text { patients } \S\end{array}$ & 61.3 & 66.1 & 0.004 \\
\hline $\begin{array}{l}\text { Raised blood pressure } \neq \text { in treated } \\
\text { patients } \uparrow\end{array}$ & 54.4 & 61.0 & $<0.0001$ \\
\hline \multicolumn{4}{|l|}{ Dyslipidaemia } \\
\hline Lipid lowering drug use & 80.4 & 77.9 & 0.83 \\
\hline $\mathrm{LDL} \geq 2.5 \mathrm{mmol} / \mathrm{l}$ in treated patients & 46.3 & 54.8 & $<0.0001$ \\
\hline \multicolumn{4}{|l|}{ Diabetes } \\
\hline Use of pharmacological treatment & 17.3 & 22.8 & $<0.0001$ \\
\hline Glucose $\geq 7 \mathrm{mmol} / \mathrm{l}$ in treated patients & 78.1 & 74.4 & 0.35 \\
\hline $\mathrm{HbA} 1 \mathrm{c} \geq 7 \%$ in treated patients & 49.6 & 63.0 & $<0.0001$ \\
\hline
\end{tabular}

Results are shown as percentages.

* Significance between sexes adjusted for age and centre.

†attending at least half of the sessions.

$\neq B P \geq 140 / 90$ or $B P \geq 130 / 80 \mathrm{~mm} \mathrm{Hg}$ for diabetic patients or treatment.

SIn patients treated with antihypertensive drugs.

qIn patients treated with any drug which may lower blood pressure (but not specifically prescribed for this reason).

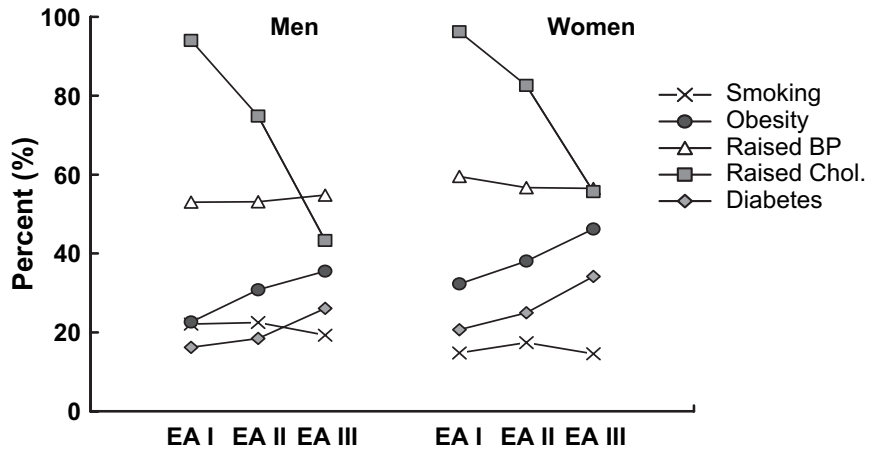

Figure 1 Trends in risk factors in men and women across the EUROASPIRE (EA) surveys. EA I: 1994-1995 EUROASPIRE surveys; EA II: 1999-2000 EUROASPIRE survey; EA III: 2006-2007 EUROASPIRE survey. The same hospitals from the same geographical areas and countries (the Czech Republic, Finland, France, Germany, Hungary, Italy, the Netherlands and Slovenia) that participated in EUROASPIRE I (1994-1995), II (1999-2000) and III (2006-2007) survey were included in this analysis. Age at inclusion was $\leq 70$ years in the three surveys. BP, blood pressure; Chol, cholesterol.

These latter trends were similar in men and women. In contrast, cholesterol control improved less in women than in men (gender-by-time interaction: $p=0.009$ ).

\section{DISCUSSION}

The goal of this study was to assess whether the implementation of demonstrably effective treatments for secondary prevention and appropriate use (estimated by achievement of therapeutic targets) were similar in men and women 6 months after hospitalisation for a coronary event or revascularisation intervention.

The EUROASPIRE surveys revealed subtle differences in the management of men and women. Antiplatelet agents and ACE inhibitors were less frequently prescribed in women than in men. Similar differences were reported in earlier reports in North America. ${ }^{9} 27$ In contrast, statins and $\beta$ blockers were prescribed to between $75 \%$ and $80 \%$ of both men and women, illustrating the potential for improvement in both genders. Renin-angiotensin inhibitors, nitrates, calcium antagonists, diuretics and insulin were more frequently prescribed in women than in men probably in relation to the higher prevalence of angina and burden of cardiovascular risk factors in women. Cardiac rehabilitation was less frequently prescribed in women than in men, but not advice for smoking cessation resulting in similarly poor control of smoking after hospitalisation. Finally, women were more likely to change their dietary habits and men appeared to prefer physical activity to control their excess body weight, reflecting traditional societal patterns.

Of the patients receiving treatment for hypertension, hypercholesterolaemia and diabetes, women were less likely to achieve and maintain the therapeutic goals. One possible explanation may be worse titration of drug treatments in the women. In agreement with this hypothesis, lower use of treatments during the acute phase of a coronary event has been reported in women, relative to men. ${ }^{16}$ This may result in less active care a long time after a coronary event. Another possible explanation is that therapeutic targets are harder to attain in women because the latter have a worse cardiovascular risk profile than men. ${ }^{9}$ For instance, women had a higher mean BMI than the men, which partly explains the greater prevalence of diabetes. Similarly, selfreported diabetes increased between the three EUROASPIRE 
Table 4 Trends in treatment prescription and achievement of treatment target in men and women across EUROASPIRE (EA) surveys

\begin{tabular}{|c|c|c|c|c|c|c|c|}
\hline \multirow[b]{2}{*}{ Per cent } & \multicolumn{3}{|l|}{ Men } & \multicolumn{3}{|c|}{ Women } & \multirow[b]{2}{*}{ p Value* } \\
\hline & $\overline{\text { EA I }}$ & EA II & EA III & EA I & EA II & EA III & \\
\hline \multicolumn{8}{|l|}{ Treatment } \\
\hline$\beta$ Blockers (\%) & 55.0 & 69.4 & 85.3 & 58.8 & 68.0 & 86.2 & $<0.0001$ \\
\hline Renin-angiotensin blockers (\%) & 30.6 & 48.7 & 74.1 & 32.2 & 50.6 & 76.1 & $<0.0001$ \\
\hline Statins $(\%)$ & 17.7 & 58.7 & 87.5 & 19.3 & 53.3 & 85.6 & $<0.0001$ \\
\hline Any BP-lowering drug (\%) & 83.5 & 90.2 & 96.6 & 87.5 & 92.0 & 97.8 & $<0.0001$ \\
\hline \multicolumn{8}{|l|}{ Control of risk among treated patients } \\
\hline $\begin{array}{l}\mathrm{SBP} / \mathrm{DBP}<140 / 90 \text { or }<130 / 80 \text { for } \\
\text { diabetics }(\%)\end{array}$ & 43.2 & 42.4 & 39.4 & 34.9 & 37.6 & 36.6 & 0.57 \\
\hline Cholesterol (<5 mmol/l) (\%) & 19.8 & 51.7 & 76.9 & 18.7 & 39.2 & 70.0 & $0.009 \dagger$ \\
\hline Fasting glucose $<6.1 \mathrm{mmol} / \mathrm{l}(\%)$ & 22.8 & 24.9 & 6.3 & 30.2 & 24.6 & 7.7 & 0.04 \\
\hline
\end{tabular}

The same geographical areas and hospitals were used in the countries (the Czech Republic, Finland, France, Germany, Hungary, Italy, the Netherlands and Slovenia) that participated in EUROASPIRE I (1994-1995), II (1999-2000) and III (2006-2007) surveys. Since the age at inclusion was $\leq 70$ years in the first two surveys, our analyses were restricted to this age class. * Significance of the time trend (differences between surveys), adjusted for age and centre.

†Significance of the gender-by-age interaction adjusted for centre.

surveys, which reflects the rise in obesity. Of particular concern, this increase over time could be partly explained by the changes in methodology for measuring glucose, but the direction of change is consistent with that for self-reported diabetes. Likewise, the more frequent use of insulin ${ }^{25} 26$ in women may reflect more advanced diabetes and thus control of glycaemia. Taken as a whole, these data highlight shortcomings in control of BP, LDL-cholesterol and diabetes in women (relative to men) after hospitalisation for a coronary event or revascularisation intervention. These shortcomings appear to be more related to suboptimal management of therapeutic targets than a lack of prescription of pharmacological agents.

Between 1994 and 2007, trends in the prescription of all cardioprotective drugs (except antiplatelet agents) were similar in women and men, suggesting that prescription of cardioprotective drugs in the past decade has not been influenced by gender. These trends were similar across different categories of index events. Only antiplatelet treatment was lower in patients included with ischemia in 1994 but the rates of prescription increased similarly in men and women. In contrast, the control of hypercholesterolaemia improved less in women than in men, further suggesting that the management of certain risk factors was and remains different between genders. In contrast, BP control was stable and that of glycaemia worsened to a similar extent in men and women over the same period of time.

This study has several strengths and limitations. The EUROASPIRE surveys were carried out in the same geographical areas and hospitals and using the same protocol. This enables valid long-term comparisons to be made. Contrary to some other surveys based on data from medical records ${ }^{18} 27$ or clinical trials, ${ }^{8}$ the patients in all EUROASPIRE centres were examined by trained staff using standardised methods, which minimised errors or recall bias. The EUROASPIRE surveys are population based, which reflects the usual medical care of patients in the community. In contrast, data from randomised clinical trials are more likely to mask gender differences, in view of the selection criteria and intensive management of associated comorbidities. Between 1994 and 2007, the definition of MI had changed (especially with the implementation of troponin assays). This leads to a certain overlap across index event definitions. ${ }^{8}$

In conclusion, our results show that after hospitalisation for a coronary event or intervention, there were no major gender differences in the pharmacological management of CHD. In contrast, women achieved the therapeutic targets for BP, LDLcholesterol and $\mathrm{HbA1c}$ less often than men. These differences were already noticed in the early 1990s and did not improve between 1994 and 2007. The EUROASPIRE results clearly point to the potential throughout Europe for raising standards in preventive cardiology, in general, and in female patients, in particular.

Acknowledgements The EUROASPIRE Study Group is grateful to all the hospitals in which the study was carried out. The investigating centre's administrative staff, doctors, nurses and other personnel helped us in many ways and we very much appreciate this. We also wish to thank the patients who participated in the study.

Funding The EUROASPIRE survey was supported with the aid of unrestricted educational grants, given to the European Society of Cardiology by the following companies: MainsSponsors: AstraZeneca, Bristol-Myers Squibb, GlaxoSmithKline, Pfizer, Sanofi-Aventis, Servier; Sponsors: Merck/Schering-Plough, Novartis.

\section{Competing interests None.}

Ethics approval This study was conducted with the approval of the ethics committee in each country.

Contributors The following authors contributed: (1) to conception and design: DDB, $\mathrm{GDB}, \mathrm{KK}$ and PA; (2) to analysis and interpretation of data: JD, DDB, JH, CP, GDB, KK, MM and PA, (3) drafting the manuscript: JD, DDB, JH, CP and MM.

Provenance and peer review Not commissioned; externally peer reviewed.

\section{REFERENCES}

1. Müller-Nordhorn J, Binting $S$, Roll $S$, et al. An update on regional variation in cardiovascular mortality within Europe. Eur Heart J 2008;29:1316-26.

2. Tunstall-Pedoe H, Kuulasmaa $\mathrm{K}$, Mähönen $\mathrm{M}$, et al. Contribution of trends in survival and coronary-event rates to changes in coronary heart disease mortality: 10 -year results from 37 WHO MONICA project populations. Monitoring trends and determinants in cardiovascular disease. Lancet 1999;353:1547-57.

3. Chambless $\mathbf{L}$, Keil U, Dobson A, et al. Population versus clinical view of case fatality from acute coronary heart disease: results from the WHO MONICA Project 1985-1990. Multinational MONltoring of Trends and Determinants in CArdiovascula Disease. Circulation 1997;96:3849-59.

4. Vaccarino V, Parsons L, Every NR, et al. Sex-based differences in early mortality after myocardial infarction. National Registry of Myocardial Infarction 2 Participants. N Engl J Med 1999;341:217-25.

5. Hochman JS, Tamis JE, Thompson TD, et al. Sex, clinical presentation, and outcome in patients with acute coronary syndromes. Global use of strategies to open occluded coronary arteries in acute coronary syndromes Ilb investigators. $N$ Engl J Med 1999;341:226-32.

6. Vaccarino V, Berkman LF, Krumholz HM. Long-term outcome of myocardial infarction in women and men: a population perspective. Am J Epidemiol 2000:152:965-73.

7. Berger JS, Brown DL. Gender-age interaction in early mortality following primary angioplasty for acute myocardial infarction. Am J Cardiol 2006;98:1140-3.

8. Berger JS, Elliott L, Gallup D, et al. Sex differences in mortality following acute coronary syndromes. JAMA 2009;302:874-82. 
9. Shaw LJ, Bugiardini R, Merz CN. Women and ischemic heart disease: evolving knowledge. J Am Coll.Cardiol 2009;54:1561-75.

10. Sheifer SE, Canos MR, Weinfurt KP, et al. Sex differences in coronary artery size assessed by intravascular ultrasound. Am Heart J 2000;139:649-53.

11. Patel H, Rosengren A, Ekman I. Symptoms in acute coronary syndromes: does sex make a difference? Am Heart $J$ 2004:148:27-33.

12. Rosengren A, Wallentin L, Gitt K, et al. Sex, age, and clinical presentation of acute coronary syndromes. Eur Heart $J$ 2004;25:663-70.

13. Vaccarino V, Krumholz HM, Berkman LF, et al. Sex differences in mortality after myocardial infarction. Is there evidence for an increased risk for women? Circulation 1995; $91: 1861-71$

14. Shaw LJ, Bairey Merz CN, Pepine CJ, et al. Insights from the NHLBI-Sponsored Women's Ischemia Syndrome Evaluation (WISE) Study: Part I: gender differences in traditional and novel risk factors, symptom evaluation, and gender-optimized diagnostic strategies. J Am Coll.Cardiol 2006;47:S4-20.

15. Bairey Merz CN, Shaw LJ, Reis SE, et al. Insights from the NHLBI-Sponsored Women's Ischemia Syndrome Evaluation (WISE) Study: Part II: gender differences in presentation, diagnosis, and outcome with regard to gender-based pathophysiology of atherosclerosis and macrovascular and microvascular coronary disease. J Am Coll Cardiol 2006:47:S21-9.

16. Chandra NC, Ziegelstein RC, Rogers WJ, et al. Observations of the treatment of women in the United States with myocardial infarction: a report from the National Registry of Myocardial Infarction-I. Arch Intern Med 1998;158:981-8.

17. Vaccarino V, Horwitz RI, Meehan TP, et al. Sex differences in mortality after myocardial infarction: evidence for a sex-age interaction. Arch Intern Med 1998; 158:2054-62.

18. Gan SC, Beaver SK, Houck PM, et al. Treatment of acute myocardial infarction and 30-day mortality among women and men. N Engl J Med 2000;343:8-15.

19. Perers E, Caidahl K, Herlitz J, et al. Treatment and short-term outcome in women and men with acute coronary syndromes. Int J Cardiol 2005;103:120-7.

20. Graham I, Atar D, Borch-Johnsen $\mathrm{K}$, et al. European guidelines on cardiovascular disease prevention in clinical practice: executive summary: Fourth Joint Task Force of the European Society of Cardiology and Other Societies on Cardiovascular Disease Prevention in Clinical Practice (Constituted by representatives of nine societies and by invited experts). Eur Heart J 2007;28:2375-414.

21. Anderson JL, Adams CD, Antman EM, et al. ACC/AHA 2007 guidelines for the management of patients with unstable angina/non-ST-Elevation myocardial infarction: a report of the American College of Cardiology/American Heart Association Task Force on Practice Guidelines (Writing Committee to Revise the 2002 Guidelines for the Management of Patients With Unstable Angina/Non-ST-Elevation Myocardial Infarction) developed in collaboration with the American College of Emergency Physicians, the Society for Cardiovascular Angiography and Interventions, and the Society of Thoracic Surgeons endorsed by the American Association of Cardiovascular and Pulmonary Rehabilitation and the Society for Academic Emergency Medicine. J Am Coll Cardiol 2007;50:e1-157.

22. Clinical reality of coronary prevention guidelines: a comparison of EUROASPIRE I and II in nine countries. EUROASPIRE I and II Group. European Action on Secondary Prevention by Intervention to Reduce Events. Lancet 2001;357:995-1001.

23. Euroaspire A. European Society of Cardiology survey of secondary prevention of coronary heart disease: principal results. EUROASPIRE Study Group. European Action on Secondary Prevention through Intervention to Reduce Events. Eur Heart $J$ 1997;18:1569-82.

24. EUROASPIRE II Study Group. Lifestyle and risk factor management and use of drug therapies in coronary patients from 15 countries; principal results from EUROASPIRE II Euro Heart Survey Programme. Eur Heart J 2001;22:554-72.

25. Kotseva K, Wood D, De Backer G, et al. Cardiovascular prevention guidelines in daily practice: a comparison of EUROASPIRE I, II, and III surveys in eight European countries. Lancet 2009;373:929-40.

26. Kotseva K, Wood D, De Backer G, et al. EUROASPIRE III: a survey on the lifestyle, risk factors and use of cardioprotective drug therapies in coronary patients from 22 European countries. Eur J Cardiovasc Prev Rehabil 2009;16:121-37.

27. Vaccarino V, Rathore SS, Wenger NK, et al. Sex and racial differences in the management of acute myocardial infarction, 1994 through 2002. N Engl J Med 2005; 353:671-82. 